\title{
Preliminary observations on the effects of 19-hydroxy prostaglandin E-1 on the activity of the human myometrium in vitro
}

\author{
J. A. Russell, P. L. Taylor* and R. W. Kelly* \\ Department of Physiology, Medical School, University of Edinburgh, Teviot Place, Edinburgh \\ EH8 9AG, and *Medical Research Council Unit of Reproductive Biology, 2 Forrest Road, \\ Edinburgh EH1 2QW, U.K.
}

\begin{abstract}
Summary. The principal prostaglandin of human semen, 19 hydroxy PGE-1, inhibited spontaneous contractile activity of myometrium from non-pregnant women in vitro. This inhibition was similar to that caused by PGE-1. The inhibitory effects of natural 19 hydroxy PGE-1, prepared from semen of Macaca arctoides, were similar to those of synthetic 19 hydroxy PGE-1.
\end{abstract}

\section{Introduction}

The major prostaglandins (PGs) in fresh human semen are 19 hydroxy E-1 and 19 hydroxy E-2 (Taylor \& Kelly, 1974; Jonsson, Middleditch \& Desiderio, 1975). PGE-1 and PGE-2 are also present (Cooper \& Kelly, 1975).

A physiological role for seminal prostaglandins has not been satisfactorily established, but one possibility is that by modifying myometrial contractile activity they aid sperm transport (Eliasson, 1959). Prostaglandins E-1 and E-2 inhibit human uterine contractions in vitro (Sandberg, Ingelman-Sundberg \& Rydén, 1963, 1964; Bygdeman, 1964; Midak, 1970). Intravenous administration of the methyl esters of 19 hydroxy PGE-1 and 19 hydroxy PGE-2 has an inhibitory effect, opposite to that of PGE-2, on uterine contractions of rabbits, but a stimulatory effect, like that of PGE-2, on uterine contractions of pregnant rhesus monkeys (Spilman, Bergström \& Forbes, 1977).

We report the results of a preliminary study of the actions of 19 hydroxy PGE-1 and PGE-1 on human myometrium in vitro.

\section{Materials and Methods}

The preparations used were PGE-1 (9-keto-11 $\alpha, 15 \mathrm{~S}$, dihydroxy prost-13-enoic acid) in the dose range 1 to $20 \mathrm{ng} / \mathrm{ml}$ bath fluid; natural 19 hydroxy PGE-1 (9 keto-11 $\alpha, 15 \mathrm{~S}, 19 \mathrm{R}$-trihydroxy prost-13-enoic acid), extracted from stump-tailed macaque (Macaca arctoides) semen, in the dose range 5 to $50 \mathrm{ng} / \mathrm{ml}$ bath fluid; and synthetic 19 hydroxy PGE-1, a mixture of racemates and epimers at $\mathrm{C} 19$, in the dose range 1 to $50 \mathrm{ng} / \mathrm{ml}$ bath fluid. The prostaglandins were dissolved in ethanol.

Pieces of myometrium were obtained from human uteri which had been removed because of fibromata or other non-malignant conditions. All were from women in their reproductive years; none was pregnant, but few other clinical details were available. From each piece of uterus 2 to 4 strips of myometrium were prepared, each $20 \times 2 \times 2 \mathrm{~mm}$. A total of 20 strips from 7 uteri was used. Each strip was mounted in an organ bath, working volume $20 \mathrm{ml}$, filled with Tyrode's 
solution (137 mM-NaCl, $2.7 \mathrm{~mm}-\mathrm{KCl}, 1 \mathrm{~mm}-\mathrm{MgCl}_{2}, 0.35 \mathrm{~mm}-\mathrm{NaH}_{2} \mathrm{PO}_{4} \cdot 2 \mathrm{H}_{2} \mathrm{O}, 12 \mathrm{~mm}-$ $\mathrm{NaHCO}_{3}, 1.8 \mathrm{~mm}-\mathrm{CaCl}_{2}, 5 \mathrm{~mm}$-glucose) kept at $36.5-37.5^{\circ} \mathrm{C}$ through which was bubbled $5 \%$ $\mathrm{CO}_{2}$ in $\mathrm{O}_{2}$ so that the $\mathrm{pH}$ was 7.3-7.4. Contractions of the strips were recorded isometrically with a $50 \mathrm{~g}$ strain gauge via an amplifier and pen recorder (George Washington Ltd, Sheerness, Kent, England). Contractile activity was measured by using a simple integrating method in which the area between the trace for three consecutive contractions and baseline was cut out with scissors and weighed. The weight of paper divided by time was used as the measure of contractile activity. This method combined measurement of frequency, amplitude and duration of individual contractions.

Spontaneous contractions usually started within 1-2 h. Three contractions were recorded in a control period then up to $5 \mu$ of a PG solution was added and left until a further three contractions had occurred or for the length of the control period if no contraction occurred; the bath was then washed out with Tyrode's solution twice and a further three contractions recorded. The next test cycle was then begun. Contractile activity during exposure to the PG was expressed as a percentage of the mean activity before and after exposure.

Each strip was exposed to at least two different PGs and to at least two doses of each PG. The lower dose of each PG was used first, but the order in which each different PG was tested was varied from strip to strip. For each dose and for each PG the mean response at each dose and the incidence of stimulation or inhibition by less than or more than $50 \%$ were calculated. These values were compared by Student's $t$ test and the $\chi^{2}$ test (with Yates' correction) respectively.

\section{Results}

Prostaglandin E-1 caused 7-100\% inhibition in all of 23 tests with doses of $2 \cdot 5-20 \mathrm{ng} / \mathrm{ml}$ (Table 1) and stimulation in 1 out of 2 tests at a dose of $1 \mathrm{ng} / \mathrm{ml}$. Both 19 hydroxy PGE-1 preparations inhibited contractions, in 41 out of 42 tests at doses of 10 and $20 \mathrm{ng} / \mathrm{ml}$ (Table 1) and in all of a further 16 tests at doses of $1,2 \cdot 5,5,30,40$ and $50 \mathrm{ng} / \mathrm{ml}$. Natural 19 hydroxy PGE-1 had no effect in one test at a dose of $10 \mathrm{ng} / \mathrm{ml}$. Vehicle alone had no effect. The mean percentage inhibition and the incidence of inhibition greater than $50 \%$ caused by PGE-1 increased significantly as the dose was increased from 2.5 to $5 \mathrm{ng} / \mathrm{ml}$ (Table 1 ) or more $(P<0.001$ and $P$ $<0.02$ respectively). The increase in the inhibitory effects of either preparation of 19 hydroxy PGE-1 with increase in dose was not significant. The synthetic, but not the natural, 19 hydroxy PGE-1 at doses of 10 and $20 \mathrm{ng} / \mathrm{ml}$ was inhibitory to a smaller extent, and by more than $50 \%$ less frequently than the same doses of PGE-1 (Table 1). The inhibitory effects of synthetic 19 hydroxy PGE-1 at 10 and $20 \mathrm{ng} / \mathrm{ml}$ were not significantly different from those of the natural preparation at the same doses.

\section{Discussion}

The present results show that 19 hydroxy PGE-1 has an inhibitory effect, similar to that of PGE1 , on the spontaneous contractile activity of human myometrium in vitro. The inhibitory effect of PGE-1 is in agreement with previous findings (Bygdeman \& Eliasson, 1963; Sandberg et al., 1963; Bygdeman, 1964; Bydgeman \& Samuelsson, 1967; Midak, 1970). The rare stimulatory effect of PGE-1 has been found previously at low doses (Sandberg et al., 1963; Eliasson, 1966; Midak, 1970). Neither natural nor synthetic 19 hydroxy PGE-1 stimulated contractile activity. The inhibitory effects of PGE-1 increased when the dose was increased from 2.5 to $5 \mathrm{ng} / \mathrm{ml}$ or more; dose-related effects have been reported previously for PGE-1 (Sandberg et al., 1964; Midak, 1970). The inhibitory effects of natural or synthetic 19 hydroxy PGE-1 did not increase 


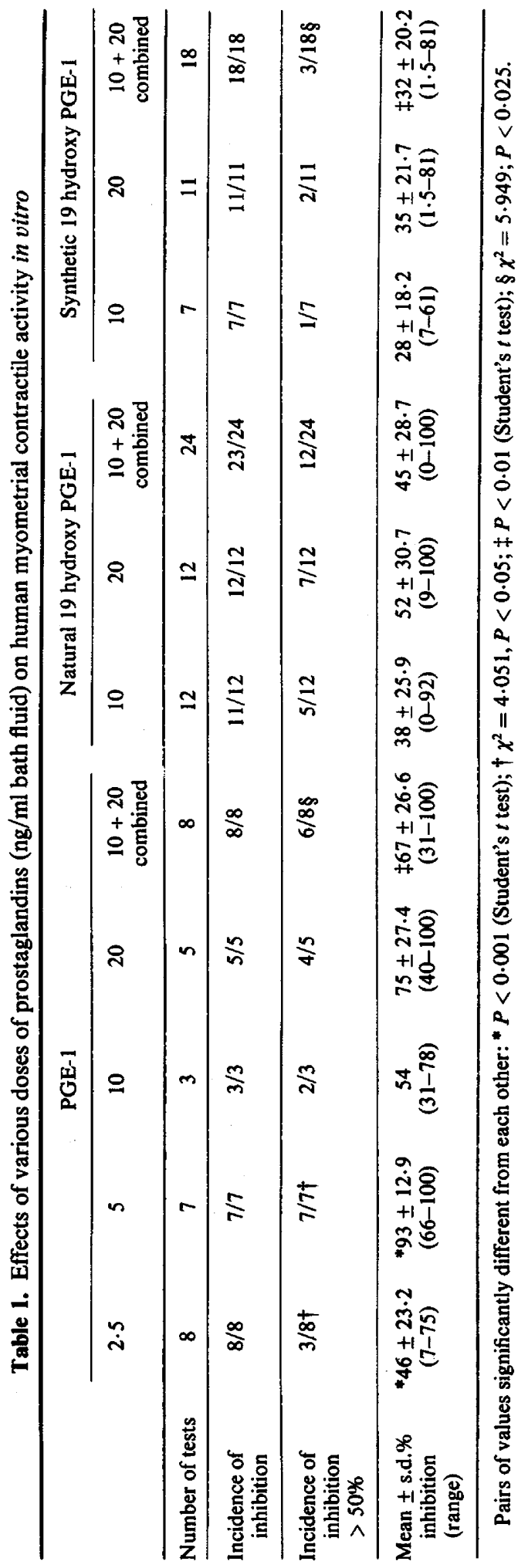


with increase in dose from 10 to $20 \mathrm{ng} / \mathrm{ml}$. Further tests with a wider range of doses have not been possible because our supply of these preparations was limited.

At doses of 10 and $20 \mathrm{ng} / \mathrm{ml}$ synthetic 19 hydroxy PGE-1 was significantly less effective than the same doses of PGE-1 although the natural preparation was not. Because the synthetic preparation was a mixture of racemates and epimers at $\mathrm{C} 19$ we expected that its biological activity might be less than that of the natural preparation, but when compared directly we found no significant difference at doses of 10 and $20 \mathrm{ng} / \mathrm{ml}$. Spilman et al. (1977) found methyl esters of 19 (R) hydroxy PGE-2 and 19 (S) hydroxy PGE-2 to be 1-2 and $0.3-0.5$ times as potent as PGE-2 respectively, when tested in vivo on myometrium of pregnant rhesus monkeys.

Normal human semen contains four times more PG of the 19 hydroxy E series than it does of the E series (Jonsson et al., 1975; Templeton, Cooper \& Kelly, 1978). Consequently our results suggest that 19 hydroxy PGE-1 is quantitatively at least as important as PGE-1 for the inhibitory effect of human semen on human myometrium in vitro.

The stage of the menstrual cycle was known for only 3 of the uteri used and we were therefore unable to examine the effects of the stage of the menstrual cycle on the response of the myometrium in vitro to prostaglandins. However, some workers have found no effects (Sandberg et al., 1963; Midak, 1970), others have found sensitivity to be maximal at mid-cycle (Bygdeman, 1964; Eliasson, 1966) and yet others have found, in vivo, a marked decrease in sensitivity around mid-cycle (Martin \& Bygdeman, 1975a, b).

We thank Professor W. E. Watson for providing facilities in the Department of Physiology; Professor R. V. Short, F.R.s. for encouragement; Dr N. S. Crossley, I.C.I., and Dr J. E. Pike, Upjohn Co., for the gifts of prostaglandins; Professor D. T. Baird and Dr R. Cole for providing uteri; and Mr H. Stuart and Miss I. Cooper for technical assistance.

\section{References}

Bygdeman, M. (1964) The effect of different prostaglandins on human myometrium in vitro. Acta physiol. scand. 63, Suppl. 242, 1-78.

Bygdeman, M. \& Eliasson, R. (1963) A comparative study on the effect of different prostaglandin compounds on the motility of the isolated human myometrium. Medna exp. 9, 409-415.

Bygdeman, M. \& Samuelsson, B. (1967) Prostaglandins in human seminal plasma and their effects on human myometrium. Int. J. Fert. 12, 17-20.

Cooper, I. \& Kelly, R.W. (1975) The measurement of E and 19-hydroxy $E$ prostaglandins in human seminal plasma. Prostaglandins 10, 507-514.

Eliasson, R. (1959) Studies on prostaglandin. Occurrence, formation and biological actions. Acta physiol. scand. 45, Suppl. 158, 1-73.

Eliasson, R. (1966) The effect of different prostaglandins on the motility of the human myometrium. Mem. Soc. Endocr. 14, 77-88.

Jonsson, H.T., Middleditch, B.S. \& Desiderio, D.M. (1975) Prostaglandins in human seminal fluid; two novel compounds. Science, N.Y. 187, 1093-1094.

Martin, J.N. \& Bygdeman, M. (1975a). The effect of locally administered $\mathrm{PGF}_{2} \alpha$ on the contractility of the nonpregnant human uterus in vivo. Prostaglandins 9, 245-253
Martin, J.N. \& Bygdeman, M. (1975b) The effect of locally administered $\mathrm{PGE}_{2}$ on the contractility of the nonpregnant human uterus in vivo. Prostaglandins 10, 253-265.

Midak, E. (1970) The action of prostaglandin $\mathrm{E}_{1}\left(\mathrm{PGE}_{1}\right)$ on human pregnant (at the time of labour) and nonpregnant uterus in vitro and modification of this action by adrenergic receptor blocking agents. Acta physiol. pol. 24, 537-550.

Sandberg, F., Ingelman-Sundberg, A. \& Rydén, G. (1963) The effect of prostaglandin $\mathrm{E}_{1}$ on the human uterus and the Fallopian tubes in vitro. Acta obstet. gynec. scand. 42, 269-278.

Sandberg, F., Ingelman-Sundberg, A. \& Rydén, G. (1964) The effect of prostaglandin $E_{2}$ and $E_{3}$ on the human uterus and the Fallopian tubes in vitro. Acta obstet. gynec. scand. 43, 95-102.

Spilman, C.H., Bergström, K.K. \& Forbes, A.D. (1977) Effects of 19-hydroxy-prostaglandins on oviductal and uterine motility. Prostaglandins 13, 795-805.

Taylor, P.L. \& Kelly, R.W. (1974) 19-Hydroxylated prostaglandins as the major prostaglandins of human semen. Nature, Lond. 250, 665-667.

Templeton, A.A., Cooper, I. \& Kelly, R.W. (1978) Prostaglandin concentrations in the semen of fertile men. J. Reprod. Fert. 52, 147-150. 